\title{
La vivencia como principio artístico- pedagógico en la formación de licenciados en artes escénicas
}

\author{
Experience as a pedagogical artistic principle \\ in the building of graduates in the performing arts
}

Angélica del Pilar Nieves Gil*; Alexánder Llerena Avendaño**

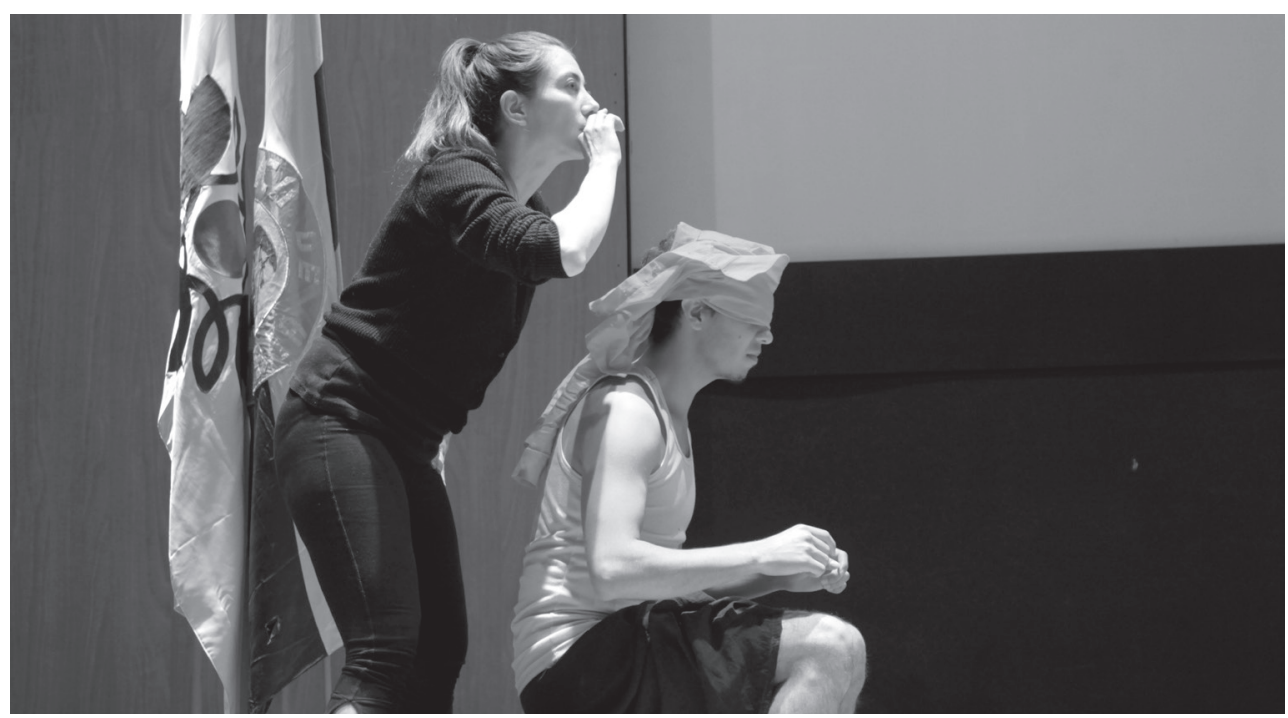

Citar este artículo como: Nieves Gil, A del P. y Llerena Avendaño, A. (2017). La vivencia como principio artístico-pedagógico en la formación de licenciados en artes escénicas. Revista Papeles, 9(18), 56-62.

Fecha de recibido: julio 1 de 2017.

Fecha de aceptación: septiembre 30 de 2017.

* Doctorante en Ciencias sobre el Arte (Universidad de las Artes, La Habana, Cuba), MA en Desarrollo Educativo y Social (Universidad Pedagógica Nacional), Especialista en Docencia del Arte Dramático, Licenciada en Danza y Teatro (Universidad Antonio Nariño). Realizó estudios de Curso de posgrado en Semiótica de la Imagen en el Instituto Superior de Artes de la Habana, Cuba (ISA). A lo largo de su trayectoria se ha especializado en la dirección de procesos de formación, investigación y proyectos de circulación en el área de las artes escénicas, posicionando la Compañía Danza Kapital en el ámbito de la danza infantil y juvenil nacional e internacionalmente en países como Bélgica, México, Chile, Perú, Bolivia, Panamá, Venezuela, Ecuador, recibiendo diferentes premios y reconocimientos como directora. Actualmente ejerce como docente investigadora en la Universidad Antonio Nariño y la Universidad Pedagógica Nacional, espacios en los que ha desarrollado importantes procesos de carácter investigativo en el campo de los estudios culturales y la pedagogía de la danza. Correo electrónico: angenieves@uan.edu.co

** Actor, director, escritor y docente de teatro. MA en Escrituras Creativas de la Universidad Nacional de Colombia. Especialista en Docencia Universitaria de la Universidad San Buenaventura. Actor, egresado de la Academia Superior de Artes de Bogotá, Facultad de Artes de la Universidad Distrital Francisco José de Caldas. Desde el año 2000 es integrante del grupo Polymnia Teatro. Desde 2014 dirige el programa de Danzas y Teatro de la universidad Antonio Nariño. Fue reconocido por el Ministerio de Cultura en 2016 con la beca a grupos de larga trayectoria para la publicación del libro Dramaturgia de Escenario, en 2015 con la beca a grupos de larga trayectoria para la temporada de repertorio Obras de Dramaturgia de Escenario, y en 2014 con la beca Itinerancias por Colombia. Correo electrónico: coordinador.danzas@uan.edu.co 


\title{
Resumen
}

Presentamos de un modo breve la concepción y fundamentación teórico-práctica del programa de la formación de profesores de las artes escénicas en la Universidad Antonio Nariño (UAN). Esta apuesta pedagógica se construye en diálogo desde planteamientos, entre otros teóricos, como el cientifismo de Dewey, hasta los antecedentes del concepto de vivencia, recogidos por la maestra Delia Zapata Olivella (con el apoyo de su hermano el antropólogo Manuel Zapata Olivella), tras años de recorrer el país y el mundo con su danza.

Palabras clave: vivencia, formación, artes escénicas, principio artístico-pedagógico.

\begin{abstract}
We present in a brief way the theoretical and practical conception and foundation of teacher training of performing arts program at the Antonio Nariño University (UAN). This pedagogical commitment is constructed in dialogue from approaches, among other theorists, such as Dewey's scientism, to the background of the concept of vivencia (experience), collected by the teacher Delia Zapata Olivella (with the support of her brother the anthropologist Manuel Zapata Olivella), after years of touring the country and the world with her dance.
\end{abstract}

Key words: experience, pedagogy, performing arts, principle in the building.

\section{Fundamentos teóricos de la construcción de artistas en hábitos pedagógicos en el programa Licenciatura en Artes Escénicas de la Universidad Antonio Nariño}

El programa Licenciatura en Artes Escénicas de la Universidad Antonio Nariño concibe la investigación como un proceso teórico-práctico que posibilita la formación interdisciplinar de los maestros-artistas, a partir del estudio profundo de la experiencia artístico-pedagógica enmarcada en los estudios de la línea de investigación didáctica de las artes escénicas.

Estos procesos investigativos, con miras a la comprensión y construcción del conocimiento, están soportados desde los planteamientos de Dewey (1995), quien establece que el conocimiento parte de la experiencia. Es a partir de las ganancias de esta postura que las dinámicas propias de trabajo del programa se orientan desde el principio de integralidad de la relación entre la teoría y la práctica.

El cientificismo de Dewey (1995) parte de considerar que todo conocimiento teórico se basa principalmente en una experiencia (método científico), pues es en ella en donde se pone a prueba la validez o no de ese conocimiento. En el marco de la formación de maestros-artistas ${ }^{1}$, esta consideración posibilita el aprendizaje a partir de la experiencia, la construcción de un pensamiento reflexivo propio, siendo parte central de este aprendizaje experiencial activo, que potencia la capacidad de generar cambios en los ambientes educativos y sus respectivos entornos.

Cuando experimentamos algo, actuamos sobre ello, hacemos algo con ello, después sufrimos o padecemos las consecuencias. Hacemos algo a la cosa y después ella nos hace algo a su vez: tal es la combinación peculiar. La conexión de estas dos fases de

1 Denominación que se da en la Licenciatura a los futuros egresados. 


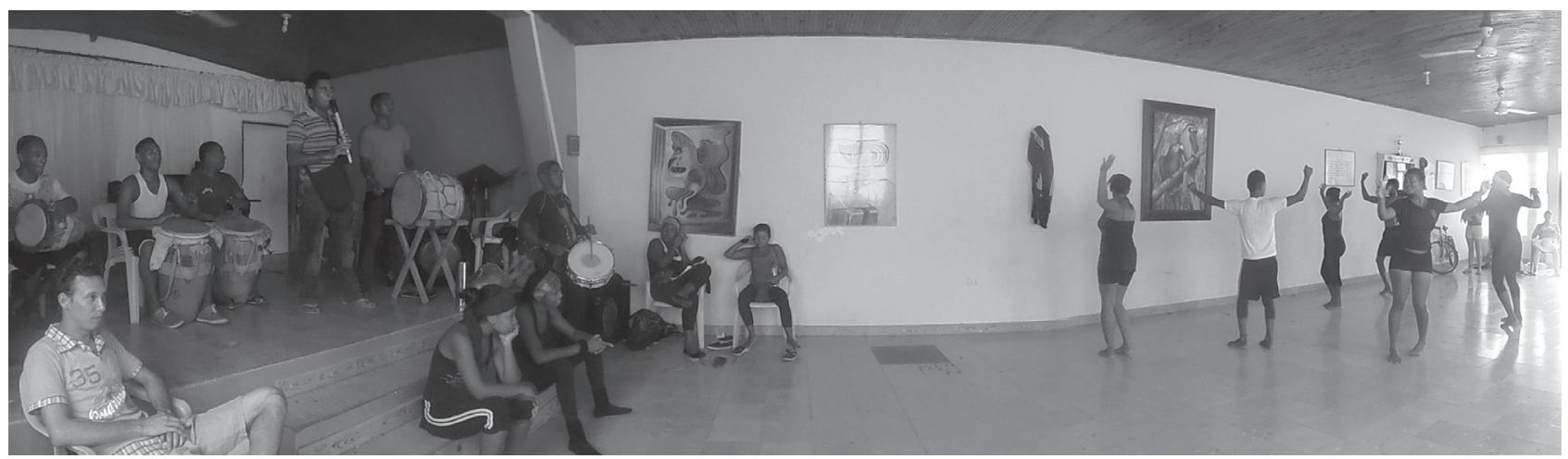

la experiencia mide la fecundidad o valor de ella. La mera actividad no constituye experiencia. Es dispersiva, centrífuga, dispersadora. La experiencia como ensayo supone cambio, pero el cambio es una transición sin sentido a menos que esté conscientemente conexionada con la ola de retorno de las consecuencias que fluyen de ella. Cuando una actividad se continúa en el sufrir las consecuencias, cuando el cambio introducido por la acción se refleja en un cambio producido por nosotros, entonces el mero fluir está cargado de sentido. Aprendemos algo. (Dewey, 1995, p. 124)

Para el programa, el maestro-artista en formación es el centro de este aprendizaje experiencial, pues es él quien se convierte en el protagonista de la acción educativa, cuya intención de aprendizaje es movida por los cuatro impulsos de Dewey (1995): el impulso social, el impulso del hacer, el impulso expresivo y el impulso de investigación. Impulsos que se visibilizan en el principio artísticopedagógico de la vivencia.

Los antecedentes del concepto de vivencia se remontan a la maestra Delia Zapata Olivella, quien con la inspiración y guía de su hermano el antropólogo Manuel Zapata Olivella recorrió el país investigando las manifestaciones dancísticas de diferentes regiones de Colombia. Investigaciones que luego la maestra llevó al campo de la creación artística, componiendo coreografías para danzas que hoy se reconocen como danzas folclóricas nacionales. El encuentro de Delia con la maestra Rosario Montaña da génesis a la Licenciatura en Artes Escénicas, que desde su origen tuvo como propósito para la formación de sus estudiantes el estudio de la tradición, indagando en las diferentes manifestaciones culturales del país con el fin de resignificar las prácticas docentes y artísticas en los colegios de Colombia.

Los antecedentes oficiales se pueden señalar en la reforma del plan de estudios de 1989, en donde se incorporó el concepto de vivencia. En este plan se destaca la incorporación de asignaturas que constituyeron los ejes disciplinares: danza tradicional colombiana y teatro. Para el año 2010 la reforma permitió la renovación del registro calificado (código SNIES 1937), esta vez caracterizado por presentar el estudio de los saberes disciplinares de la danza, el teatro y su pedagogía desde una metodología teóricopráctica.

La vivencia, entendida como una experiencia de carácter investigativo al estado actual de la tradición de las diferentes culturas de nuestro país, posibilita el acercamiento, la indagación y la reflexión en torno a las tradiciones vivas en las poblaciones portadoras a lo largo del territorio nacional, se ha configurado como una forma de aprendizaje experiencial que permite a sus participantes (maestros-artistas) vivir y reconocer afectaciones de tipo sensible, afectivo, social y cognitivo que redunda en sus prácticas artístico-pedagógicas. En esta 
medida se hace posible sentir y comprender la experiencia que se constituye en propia en el transcurrir de los acontecimientos y sucesos, produciendo en sus participantes efectos, marcas y huellas, reflejadas en interpretaciones cargadas de múltiples significados.

Teniendo como punto de partida la trayectoria y el impacto de la vivencia en nuestra licenciatura desde su creación, este proyecto pretende dar cuenta de los procesos artístico-pedagógicos-investigativos que se desarrollan al interior de las asignaturas, los productos que de estos se derivan a partir del cubrimiento regional que a lo largo del tiempo se ha desarrollado en las fiestas, festivales, carnavales y demás manifestaciones culturales de Colombia.

En el plan de estudios vigente, los maestrosartistas en formación cursan asignaturas de los ejes disciplinares (danza y teatro), en las que se realizan trabajos de campo de corte etnográfico, diseñado en los contenidos programáticos y que de acuerdo al nivel de formación del maestro-artista cumple con diferentes niveles de complejidad respecto a la formación y cualificación en los procesos investigativos de la tradición.

En la actualidad, la vivencia, además de concebirse como principio artístico-pedagógico, desde el año 2009 se configura como uno de los proyectos transversales que adelanta el grupo de investigación Didáctica de las artes escénicas, de la Facultad de Educación.

Dada la naturaleza experiencial de este proyecto, se hace necesario que sus participantes sean susceptibles a afectaciones causadas por otras culturas diferentes a la propia, que se permitan interactuar y establecer vínculos con las diversas manifestaciones socioculturales y estéticas. Es así, y solo así, como posteriormente estos participantes sufrirán las consecuencias de la transformación enunciada por Dewey (1995), en beneficio de la formación profesional colectiva e individual de los maestros-artistas.

Estas experiencias se configuran como espacios genuinos para que los maestros-artistas vivan in situ las manifestaciones tradicionales y populares de las culturas estudiadas, logrando relacionar y contrastar la información trabajada en las clases teórico-prácticas, alcanzando así la construcción de un conocimiento enriquecido por la interacción con las personas oriundas de las culturas, mediante la observación participante en las prácticas artísticas y culturales (danzarías, teatrales, musicales, plásticas, literarias, gastronómicas entre otras) de las fiestas y carnavales de nuestro país. Esta dinámica de aprendizaje experiencial se desarrolla de forma sistemática mediante la recolección de información a partir de técnicas pertinentes, producto de un trabajo previo a las salidas de campo, planeado y organizado en clase, en donde se diseñan objetivos, instrumentos de recolección de datos, planes de trabajo, entre otros.

En estas vivencias no solamente se recoge información, sino que además se realizan intercambios formativos entre grupos; o, si las condiciones de la fiesta o carnaval lo permiten, se realiza una participación artística-escénica de representación institucional. Desde esta perspectiva teórica-práctica se espera que el maestro-artista en formación asuma una postura crítica y propositiva desde su rol,

\footnotetext{
El maestro-artista en formación se convierte en el protagonista de la acción educativa, cuya intención de aprendizaje es movida por los cuatro impulsos de Dewey: el impulso social, el impulso del hacer, el impulso expresivo y el impulso de investigación. Impulsos que se visibilizan en el principio artístico-pedagógico de la vivencia.
} 
alimentándose de la tradición al entenderla como un fenómeno sociocultural vivo $\mathrm{y}$ cambiante.

La vivencia como principio artísticopedagógico se cimienta en los desarrollos investigativos de la pedagogía del arte. En las últimas décadas esta forma investigativa se ha constituido en una opción particular que se ha abierto espacio en el ámbito de la investigación científica de una manera singular, pues se ha separado de las formas hegemónicas que se sustentan en la aplicación de procedimientos. La investigación en arte se orienta bajo el propósito de dar respuesta a las necesidades propias de poblaciones y disciplinas que buscan abordar procesos de indagación, análisis, reflexión de realidades de naturaleza experiencial, por ello trata asuntos en torno al significado sociocultural de los comportamientos y experiencias humanas, sus relaciones y representaciones simbólicas vistas a la luz del arte y sus hacedores.

En esta misma línea de investigación, camino a concebir la investigación en el arte en un mundo de pensamiento positivista-racionalista, es preciso situar los planteamientos que el pensamiento construccionista ha realizado a su favor (Gergen, 2000 e Ibáñez, 2003).

a. Los orígenes sociales del saber residen en las relaciones interpersonales. Este

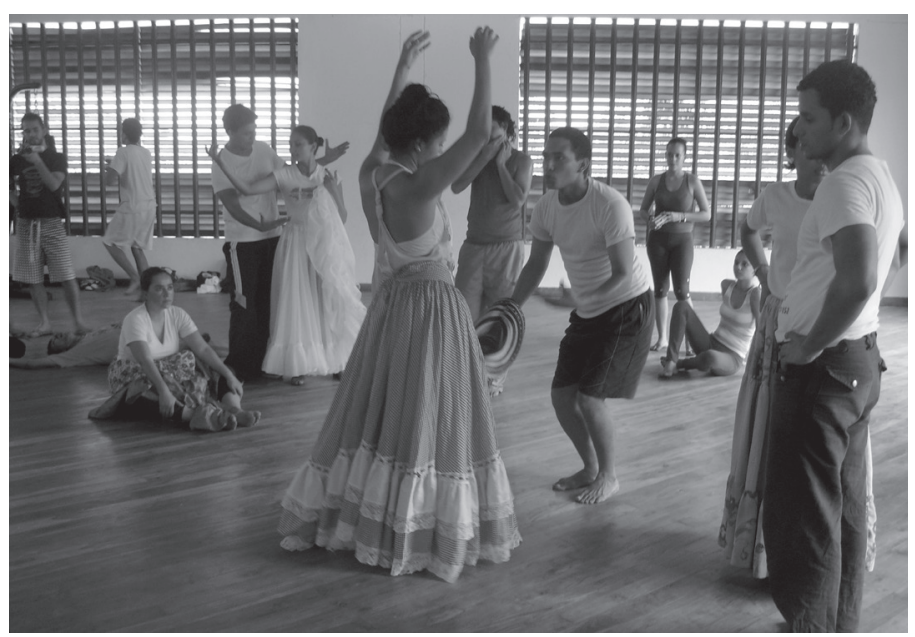

planteamiento se convierte en cimiento del aprendizaje experiencial, forma en la que particularmente en el programa se generan los procesos de construcción de conocimiento, pues es en estas interrelaciones que los maestros-artistas encuentran las atmósferas para el desarrollo de los laboratorios que les permiten acceder a experiencias de aprendizaje vivencial y lograr la contrastación con los fundamentos teóricos.

b. La influencia central del lenguaje. El lenguaje posibilita la comprensión del mundo. El lenguaje entendido en dos sentidos complementarios, no solo como aquella palabra enunciada o escrita que es muy importante desde el lugar de la tradición oral, sino también el lenguaje de los cuerpos, pues en ellos se pueden leer las huellas de una historicidad cultural. El diálogo y estudio de estos lenguajes en diferentes culturas hace que el programa se cuestione sobre este, con el propósito de alcanzar la comprensión de los asuntos artísticos y culturales estudiados.

c. Elenvite político del saber: la distinción entre hechos y valores es indisoluble. La naturaleza del estudio de diversas manifestaciones culturales visibiliza la indisoluble relación entre los valores y los acontecimientos, pues los segundos son consecuencia de los primeros. En el ámbito de la tradición cultural de manera consciente o inconsciente las acciones individuales y colectivas son determinadas por aquellos valores que a lo largo de la historia se han ido configurando en la constitución de los diferentes grupos humanos.

d. El yo en la relación: lo que está en la mente es un efecto de la esfera social. En el campo de la cultura se concibe al sujeto como aquel que ha sido constituido por los rasgos que día a día se configuran en la convivencia de un grupo humano particular; es así como el "yo" se convierte en una representación de todas aquellas singularidades que se entretejen en la esfera social en la que habito. 
En la línea de comprender la investigación en esa relación entre la teoría y la práctica, el programa encuentra en los planteamientos de Bruner (1998, los cuales que son citados por Bolívar y Domingo, 2006) interesantes argumentos que brindan base teórica a esta concepción. Existen dos modalidades para comprender el conocimiento y la creación humana: la pragmática, que busca la experiencia basándose en la prueba lógica, el análisis razonado, la observación empírica. Y la narrativa, centrada en las intenciones, experiencias, necesidades y deseos humanos. Para Bruner (citado en Bolívar y Domingo, 2006), el equilibrio entre estas dos modalidades es esencial para una construcción identitaria. Para el programa es importante reconocer esta relación presentada por el autor, considerando que abre caminos para nuevas formas de investigación, pues sustenta la alta importancia de comprender al ser humano en su contexto y las relaciones que se tejen en él, mediante un ejercicio riguroso de fundamentación teórica y análisis, en dinámica con procedimientos propios que se ajusten a las complejas situaciones humanas dado su carácter de transformación y singularidad.

Las ideas de Bruner abren las puertas a concebir nuevas formas de investigación etnográfica, biográfica, histórica, narrativa, performativa, (...) formas que de una $\mathrm{u}$ otra forma han abierto el espacio para que la investigación en el arte se asome al campo científico (Bruner 1998, citado en Bolívar y Domingo, 2006).

En línea con lo anterior encontramos a Eisner (1998), quien realiza una entrada concreta al campo de la pedagogía del arte:

abrir nuevas vías de pensamiento sobre cómo llegamos a saber y exploramos las formas, a través de las cuales lo que sabemos se hace público. Tales formas, como la literatura, el cine, la poesía y el vídeo se han utilizado durante años en nuestra cultura para ayudar a que las

\section{Para el maestro-artista en formación, la investigación en arte se convierte en el acontecimiento de hacer arte, una forma de comprender el asunto investigado.}

personas vean y comprendan cuestiones y acontecimientos importantes. En raras ocasiones se han utilizado en la realización de investigación educativa. Estudiamos la enseñanza con herramientas estadísticas muy poderosas, pero rara vez la estudiamos también como un arte práctico. Mi propósito es plantear otros modos de ver cómo puede realizarse la indagación en cuestiones educativas. (1998, p. 283)

Eisner (1998) plantea el arte como una experiencia humana genuina, basado en la tradición de Dewey, llevando a Sullivan (2004) a proponer un enfoque de investigación que posibilitó teorizar la práctica de las artes visuales.

La pedagogía del arte parte de la indagación sobre los procesos creativos (literarios, artísticos y performativas) y sus formas de interpretación; procesos en los que el investigador en artes se mueve entre las formas del conocimiento emocional y cognitivo, según lo menciona Mullen (2003). Esta nueva forma de investigación se caracteriza por el uso de elementos artísticos y estéticos, la búsqueda de otras maneras de mirar y representar la experiencia, develar aquello de lo que no se habla.

Para el maestro-artista en formación, la investigación en arte se convierte en el acontecimiento de hacer arte, una forma de comprender el asunto investigado, por tanto, una forma de hallar el significado de las prácticas de la enseñanza. En este proceso de investigación en arte el maestro-artista desarrolla habilidades como: 
- La reflexividad, en la medida en que posibilita que este pueda dar mirada hacía el proceso vivido desde una posición crítica, en la que puede realizar los respectivos análisis y luego continuar su camino tomando como punto de partida el lugar de la reflexión, ascendiendo, así, en una espiral crítico-reflexiva.

- La destreza de comprender lo ordinario como acontecimiento extraordinario, en la medida en que provoca, innova y quiebra resistencias, llevándonos a considerar nuevas maneras de ver o hacer cosas.

- Entraña corporeización y provoca respuestas corporeizadas, pues ubica al "yo" del investigador en un lugar vivencial en el que necesariamente será afectado y transformado por la experiencia.

En este sentido, la vivencia como principio artístico-pedagógico permite configurar la triada interdisciplinar del maestro-artistainvestigador. Es decir, dado su carácter de aprendizaje experiencial nutre un ámbito específico de investigación en arte, que, partiendo de la etnografía, la trasciende por la naturaleza del acontecimiento del encuentro sensible, avanza de la racionalidad del método científico hacia la construcción de posibilidades para la creación, a partir del estudio de la tradición.

\section{Referencias}

Bolívar, A., y Domingo, J. (2006). La investigación biográfica y narrativa en Iberoamérica: Campos de desarrollo y estado actual. In Forum: Qualitative Social Research Vol. 7, 1-43.

Dewey, J. (1995). Democracia y educación: una introducción a la filosofía de la educación. Madrid: Ediciones Morata.

Eisner, E. W. (1998). El ojo ilustrado. Indagación cualitativa y mejora de la práctica educativa. Barcelona: Paidós.
Gergen, K. J. (2000). Toward a postmodern psychology. Psychology and Postmodernism, 17-30.

Ibañez, T. (2003). La construcción social del socioconstruccionismo: retrospectiva y perspectivas. Politica y sociedad, 155-160.

Mullen, Carol A. (2003). A self-fashioned gallery of aesthetic practice. Qualitative inquiry, Guest editor's introduction, 9(2), University of South Florida.

Sullivan, G. (2004). Art Practice as Research Inquiry in the Visual Arts. Nueva York: Teachers College, Columbia University. 